論文 Memoirs

\title{
The Structure and the Energy of Typhoons
}

\author{
By K. Takahashi, T. Watanabe, S. Kubota \\ T. Ando and N. Nakamura \\ (Meteorological Research Institute)
}

\section{Contents}

\begin{abstract}
Preface
\end{abstract}
\$ 1. Tropical low pressure area, south coast of Japan in August 1950

$\S 2$. Dynamics of the eye of a typhoon

$\S 3$. Distribution of surface wind velocity in a typhoon

$\S 4$. Relation between the wind center and the pressure center
$\S$ 5. Wind and converging air current in a typhoon

§ 6. Energy equation

$\S 7$. Estimation of various energies of typhoons

§ 8. Energies of the typhoons Kitty and Kezia

$\S 9$. Damages caused by the typhoons and their magnitude

\section{Preface}

Summer pressure patterns of 1950 around Japan were rather abnormal, and several midget typhoons developed over tropical low pressure area off the south coast of Japan. On September $3 \mathrm{rd}$, the Typhoon Jane landed on the Kinki District and a high tide occurred.

The present paper is a brief summery of our studies on the structure and the energy of typhoons, for the purpose of explaining the characters of the typhoons of the summer of 1950. Details will be published in Japanese in the Memoirs of the Central Meteorological Observatory.

\section{$\$$ 1. Tropical low pressure area, south coast of Japan in August 1950}

S. Kubota studied the mean state of tropical low pressure area during August and on several characteristics of the disturbances superposed on it.

At first, to find the general atmospheric state of this summer in low latitudes, the various averages of the data observed by radiosonde and rawin from 1 st to 18 th were computed. The contours of isobaric surfaces and isotherms at $850 \mathrm{mb}, 200 \mathrm{mb}$ and $100 \mathrm{mb}$ levels are shown in Fig. 1.1, and various cross sections are also shown in Fig. 1.2. The following results are obtained by the aid of these charts. (1) The tropical low pressure area displaces towards east with elevation. (2) Above $300 \mathrm{mb}$ level there is a distinct cold trough extending from $\mathrm{NNE}$ to SSW, $i . e$, the pressure over the tropical low pressure area is high. (3) The $100 \mathrm{mb}$ chart shows that in the stratosphere the southern part of the above trough is of cold type, while the northern part is of warm type. 
Fig. 1.1 (a)
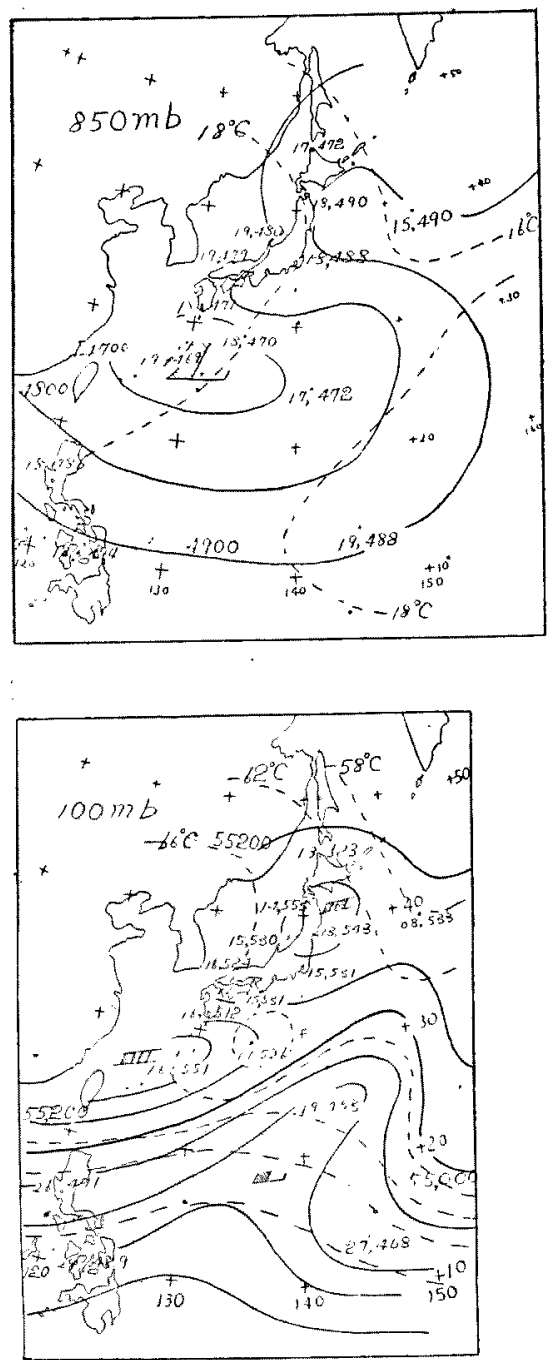

Fig. 1.1 (c)
Fig. 1.1 (b)
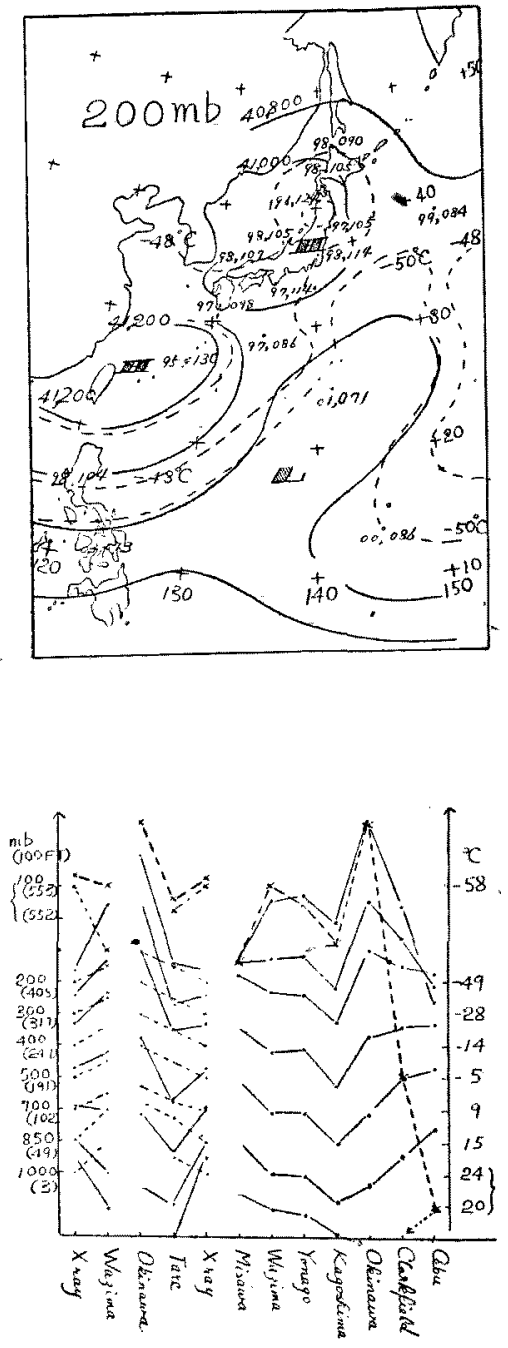

Fig. 1.2

From the vertical distribution of upper wind in Fig. 1.3, the following results can be recognized. (1) There exists little change of wind velocity with elevation from the surface up to $30,000 \mathrm{ft}$ level. (2) The wind velocity east of upper high is weak. (3) The wind velocities of both sides of upper trough show maxima at $200 \mathrm{mb}$ level and minima just under the tropopause, and increase again in the stratosphere. (4) Weak wind layers exist between 20,000 and $30,000 \mathrm{ft}$ levels. The winds in both sides of these layers occasionally change discontinuously. (5) Over Guam and Clarkfield strong easterlies prevail in the upper layer and strong westerlies below $30,000 \mathrm{ft}$ over Clarkfield. (6) The weak easterlies over 
Kwajelein and Eniwetok change little with elevation. (7) A singular layer is found in which the wind speed is everywhere $13 \mathrm{knots}$, and the height of this layer is about $20,000 \mathrm{ft}$ over the western part of upper high and $30,000 \mathrm{ft}$ over the eastern part of it. (8) And the easterlies prevail in the stratosphere in low latitudes.

Tropical low pressure area is generally accepted to be of cold type and when the strength of cyclonic circulation increases the type changes into a warm one. However, the midget typhoons which were formed in the low pressure area this summer were mostly of cold type, and the heights of these disturbances were variable.

A midget typhoon passed over the ocean weather station Tare (29.5 N. $135 \mathrm{E}$.) in the afternoon of September 9 th.

Temperature curves (Fig. 1.4) show that the temperature decrease of about $10^{\circ} \mathrm{C}$ occurred in the middle layers from the noon of 9 th to the morning of $10 \mathrm{th}$, and the stable atmosphere between 800 $\mathrm{mb}$ and $700 \mathrm{mb}$ levels at $12 \mathrm{~h} 8$ th changed into an unstable atmosphere. And the relative humidity

Fig 1.3 (a)

Vertical distribution of mean wind relocity.

(Stations to the west of upper anticyclonic circulation)
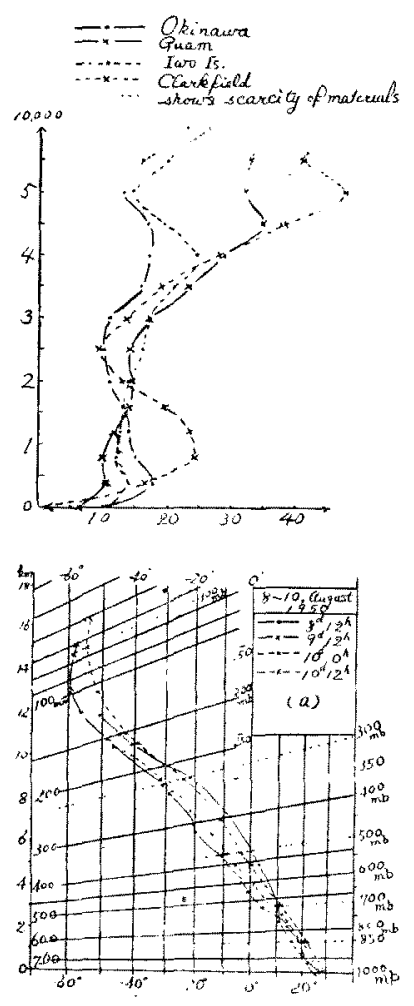

Fig. 1.4 (a)
Fig. 1.3 (b)

Vertical distribution of mean wind velocity. (Stations to the east of upper anticylconic circulation)
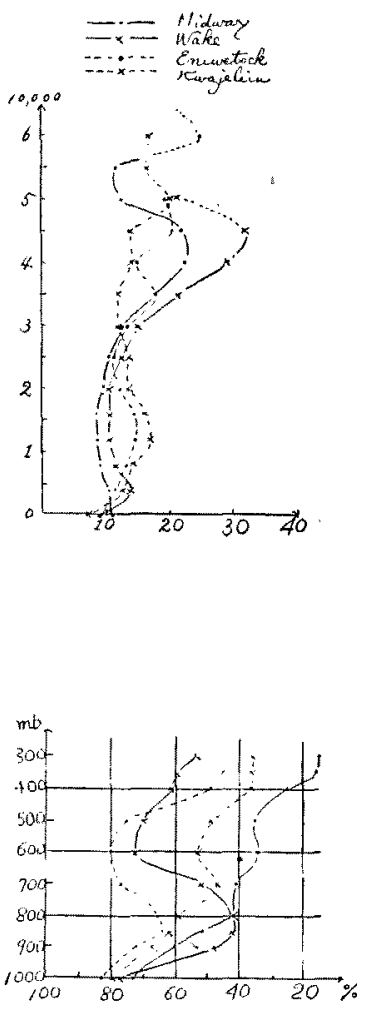

Fig. 1.4 (b)

Humidity curves. was always low, increasing a little as it passed.

According to the distribution of isobaric and isothermal surfaces in the time cross section (Fig. 1.5), the baroclinicity is seen below $700 \mathrm{mb}$ level over station Tare.

Lastly it may be worth to note that the influence of the solar radiation on the observed data of radiosonde is negligible, especially in average. The effects of solar radiation are rather reversed in the tropical low pressure area. Over station Tare the average temperature at noon is about $1^{\circ} \mathrm{C}$ lower than that in the morning from the surface up to $500 \mathrm{mb}$ level. And the heights of tropopause over various stations are higher in the morning than 
in the aftermoon.

\section{\$ 2. Dynamics of the eye of a typhoon}

T. Watanabe studied the eye of typhoon. Assuming a homogeneous, incompressible and barotropic atmosphere, the motion of an air particle is expressed by the well known relations,

$$
\begin{aligned}
& \Omega \equiv r\left(v_{\theta}+\frac{\lambda}{2} r\right)=\text { const. } \\
& \text { for an air particle, } \\
& P \equiv p+\frac{\rho}{2}\left(v_{\theta}^{2}+v_{r}^{2}\right)=\text { const. }
\end{aligned}
$$

for an air particle,

where $\Omega$ is the absolute angular momentum, $P$ the total pressure, $v_{\theta}, v_{r}, r$ are used as usuai and $\lambda$ the Coriolis parameter assumed to be constant.

If the motion of air particles is obtained, divergence, vorticity, vertical velocity, etc. in a typhoon can be calculated. In Fig. $2 \cdot 1$ the variation of stream lines in a given concentric ptessure distribution which approximately represents a typhoon is shown. The particles move tow ards the center spirally and reach a certain convergence circle, but can not enter within it, and vertical currents are large at. the vicinity of the convergence circle, and the following relation holds, (1)

$$
\frac{u^{\prime}}{Z_{x}}=\frac{v^{\prime}}{Z_{y}}=\frac{w}{Z_{z}}
$$

(1) The equations of motion in dynamic meteorology are described as follows;

where

$$
-Z_{z} v+Z_{y} w=-\frac{\partial Q}{\partial x}, \quad-Z_{x} w+Z_{z} u=-\frac{\partial Q}{\partial y}
$$

and

$$
Q=\int \frac{d p}{\rho}+\frac{1}{2}\left(u^{2}+v^{2}+w^{2}\right)
$$

$$
u=-\frac{1}{Z_{z}} \frac{\partial Q}{\partial y}+u^{\prime}, \quad v=+\frac{1}{Z_{z}} \frac{\partial Q}{\partial x}+v^{\prime}
$$

From the above four relations, expression (2.1) is deduced, which is very important and useful
Fig. 1.5
Fig. 2.1.

Stream line field at $t=+0 \mathrm{sec}, 10^{4} \mathrm{sec}$ and $2 \times 10^{4} \mathrm{sec}$.

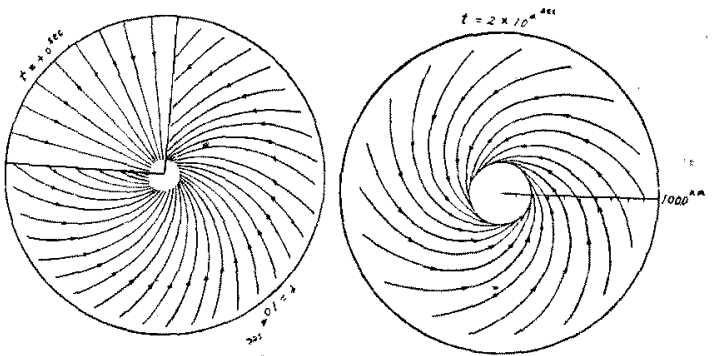


where $u^{\prime}, v^{\prime}$ are the deviations from the gradient wind and $\left(Z_{x}, Z_{y}, Z_{z}\right)$ the components of absolute vorticity.

Therefore the vertical current system is inclined approximately to the north, and the convergence line is of elliptic form. The same dynamical mechanism is expected also within the convergence circle, hence a multiple eye may be generated at the initial state of the eye. Thus the above theoretical conclusions are in good agreement qualititavely with many observed phenomena in the eye.

Next, the maintenance of the eye of a developed typhoon is explained by the effect of surface friction. The horizontal convergence due to surface friction is almost determined by the so called frictional term,

$$
Q=-\frac{\nu}{\zeta+\lambda} \frac{\partial^{2} \zeta}{\partial z^{2}}
$$

which is related to the vertical distribution of the vertical component of vorticity $\zeta$. Since the vorticity decays by surface friction, the horizontal convergence decays also by the same effect. This theoretical results correspond to the enlargement of the eye on land.

\section{$\$ 3$. Distribution of surface wind velocity in a typhoon}

K. Takahashi and R. Ito studied the distribution of surface wind velocity. Assuming

Fig. $3 \cdot 1$

Distribution of wind velocity in typhoons.
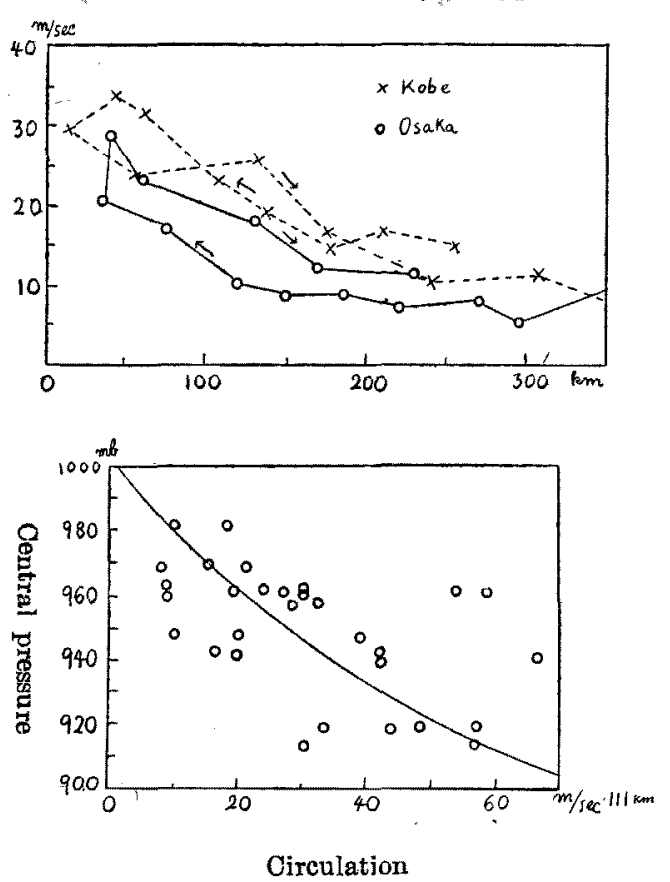

Fig. 3.2 that typhoons are stationary and almost of circular symmetry, the relation between the wind velocity $v$ and the distance from the center of typhoon $r$ is plotted in graphs for several "typhoons. One example is shown in Fig. 3.1. We see that the following empirical formula proposed by Dr. Horiguti holds in good approximation.

$$
v=A / \sqrt{ } \bar{r}
$$

Within the internal area of a typhoon, the

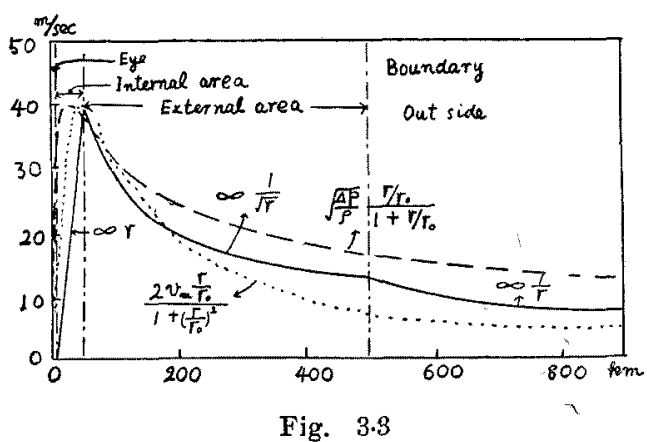

A model of wind distribution in typhoons. 
above formula holds no longer and the empirical formula becomes

$$
v=B r .
$$

The radius of such an internal area of typhoons is about $30-40 \mathrm{~km}$. On the other hand, the empirical formulae $(3 \cdot 1),(3 \cdot 2)$ are not applicable outside of the typhoon area, and the following empirical formula holds.

$$
v=C / r
$$

where $C$ is the circulation of the wind. It is interesting that the circulation depends on the central pressure of the typhoons as shown in Fig. 3.2 and we have a model of surface wind distribution as shown in Fig. 3.3.

Next, we consider theoretically the meaning of the empirical formula (3.4). We assume that the absolute circulation $C_{a}$ of the wind around the center of typhoons is conservative,

$$
C_{a}=C+\frac{\lambda^{2}}{2}
$$

where $\lambda$ is the Coriolis parameter. But in our case the change of the absolute circulation is considered to be caused by surface friction and horizontal mixing, and they are expressed. as follow:

$$
\frac{d C_{a}}{d t}=-\frac{\kappa}{H} v^{2} r+\frac{\eta}{r} \frac{\partial}{\partial r} r \frac{\partial C_{a}}{\partial r}
$$

where $H$ is the height of typhoons, $\kappa$ the coefficient of surface friction, $\eta$ the coefficient of horizontal mixing.

When typhoons are stationary, (3.5) becomes

$$
\frac{1}{r} \frac{\partial}{\partial r} r \frac{\partial C}{\partial r}+2 \lambda=\frac{\kappa}{\eta H} \frac{C^{2}}{r}
$$

If the first term is negligible,

$$
C=\sqrt{\frac{2 \lambda \eta H r}{\kappa}} \text { or } \quad v=\sqrt{\frac{2 \lambda \eta H}{\kappa r}} .
$$

This agrees with $(3 \cdot 1)$. If we put

$$
\kappa=5 \times 10^{-3} \text { C. G.S., } \quad H=10 \mathrm{~km}, \quad \eta=10^{10} \text { C. G. S., } \quad \lambda=7 \times 10^{-5} \mathrm{sec}^{-1},
$$

we qet:

$$
v=50 \mathrm{~m} / \mathrm{sec} / \sqrt{r},
$$

where unit of $r$ is $111 \mathrm{~km}$. The first term of $(3 \cdot 6)$ can not be neglected when $r$ is smaller than a certain value. This value is calculated as follows:

and

$$
\frac{1}{r} \frac{\partial}{\partial r} r \frac{\partial C}{\partial r} \approx \sqrt{\frac{\lambda \eta H}{8 \kappa}}
$$

$$
r=\left(32-\frac{\kappa \lambda}{\eta H}\right)^{-1 / 3}
$$


Numerical value of the above $r$ is $40 \mathrm{~km}$ which is in good accordance with the radius of the internal area of typhoons.

\section{\$ 4. Relation between the wind center and the pressure center}

T. Watanabe studies the relation between the wind and the pressure center.

Assuming a homogeneous and incompressible atmosphere, the equations of motion are described as follows;

$$
\frac{\partial u}{\partial t}+u \frac{\partial u}{\partial x}+v \frac{\partial u}{\partial y}-\lambda v=-\frac{1}{\rho} \frac{\partial p}{\partial x} . \quad \frac{\partial v}{\partial t}+u \frac{\partial v}{\partial x}+v \frac{\partial v}{\partial y}+\lambda u=-\frac{1}{\rho} \frac{\partial p}{\partial y}
$$

Assuming further a stationary (circular) pressure system moving with constant velocity $c$ along the $x$-axis, the following equations will be obtained,

$$
-Z V=-\frac{1}{\rho} \frac{\partial Q}{\partial x}, \quad+Z U=-\frac{1}{\rho} \frac{\partial Q}{\partial y}
$$

where $U=u-c, V=v$ are the velocities relative to the typhoon;

$$
\begin{gathered}
Z=\frac{\partial V}{\partial x}-\frac{\partial U}{\partial y}+\lambda=\frac{\partial v}{\partial x}-\frac{\partial u}{\partial y}+\lambda, \\
p^{*}=p+\rho \lambda c y, \quad Q=p^{*}+\frac{\rho}{2}\left(U^{2}+V^{2}\right) .
\end{gathered}
$$

From $(4 \cdot 1)$, we see that the relative stream lines coincide with the iso- $Q$ lines, and also approximately with the iso $-p^{*}$ lines (see Fig. $4 \cdot 1$ ).

If we put $R$ the distance between the pressure center and the wind center, $R$ is determined by the following relation, since at the wind center the relative wind velocity $U=-c$,

$$
\frac{c^{2}}{R}-\lambda c \doteqdot-\frac{1}{\rho} \frac{\partial p^{*}}{\partial y}
$$

or

$$
R=-\frac{c^{2}}{\frac{1}{\rho} \frac{\partial p}{\partial y}}=\frac{c^{2}}{\lambda v_{g}}
$$

where $v_{g}$ is the geostrophic wind in a concentric cyclone. For usual typhoons $\frac{\partial v_{g}}{\partial z}<0$, so the distance $R$ increases with the height and its maximum value is about $100 \sim 150 \mathrm{~km}$ (in the upper layer).

If there is a uniform general current $G$, a pressure distribution $p(r)-\rho \lambda G y$ is used instead of $p(r)$, and $Q^{\prime} \equiv p(r)+\rho \lambda(c-G) y+\frac{\rho}{2}\left(U^{2}+V^{2}\right)$ is used instead
Fig 4.1

Oircular cyclone (after Dr. Wadati) and iso- $p^{*}$ lines, which agree with the exact relative stream lines due to Dr. Wadati; where $c=30 \mathrm{~km} / \mathrm{h}, \lambda=10^{-4}$ and $\rho=10^{-3} \mathrm{C}$. G. S.

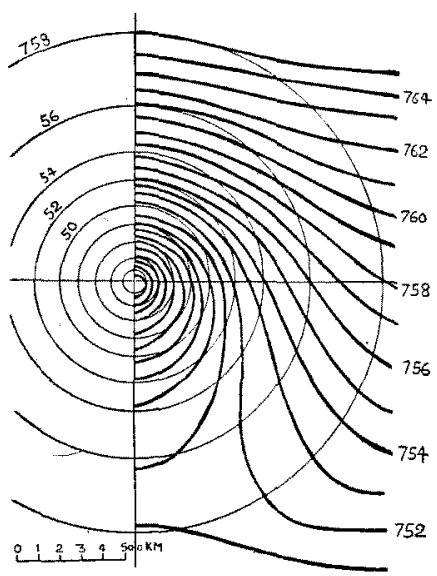


of $Q$. Therefore, there are three cases. The 1 st case $G<c$; the essential features are the same with the above results. The 2 nd case $G=c$; the effects due to the motion of cyclone and the general current are compensated, and the wind center coincides always with the pressure center. The $3 \mathrm{rd}$ case $G>c$; the relative streamlines are symmetry with the 1 st case in relation to $x$-axis, therefore the wind center is on the opposite side.

\section{$\$$ 5. Wind and converging air current in a typhoon}

N. Nakamura calculated the motion of air particles in a typhoon.

If the isobars are of axial symmetry, the equations of air particles are expressed in polar coordinates as tollows;

$$
\begin{gathered}
\frac{d v_{r}}{d t}--\frac{v_{\theta}^{2}}{r}-\lambda v_{\theta}=-\frac{1}{\rho} \cdot \frac{\partial p}{\partial r}-k v_{r} \\
\frac{d v_{\theta}}{d t}+\frac{v_{r} \cdot v_{\theta}}{r}+\lambda v_{r}=-k v_{\partial}
\end{gathered}
$$

where $v_{r}$ is the radial velocity, $v_{\theta}$ the tangential velocity, $\lambda$ the Coriolis parameter, $\rho$ the density of air and $k$ the coefficient of friction.

If the distribution of $p$ is given, $v_{r}$ and $v_{\theta}$ are calculated by the above equations, but, it is very difficult when $k \neq 0$. On the other hand, if $v_{r}$ and $v_{d}$ are given, the pressure gradient is casily calculated. Accordingly, the pressure distribution was calculated assuming that $v_{\text {: and }} v_{\theta}$ are given, and then the motion of air particles in the calculated pressure distibution was obtained assuming $k=0$. It was found that these two motions of an air particles are approximately equal, bence, the effect of friction is negligible at least when we deal with the, motion at the beginning.

Let the pressure distribution in typhoons be of Prof. S. Syono's model, and the initial conditions of an particle be $r_{0}=500 \mathrm{~km}, v_{\theta_{0}}=0, v_{i n}=0, p_{0}=1000.2 \mathrm{mb}$.

If we assume that the pressure distribution is stationary and friction is zero, $v_{r}$ and $v_{\theta}$ are easily calculated by the following equations.

$$
\begin{aligned}
& p+\frac{1}{2} \rho\left(v_{r}{ }^{2}+v_{\theta}{ }^{2}\right)=p_{0} \quad \text { (Bernoulli's theorem) } \\
& v_{\theta}=\frac{\Omega_{0}}{r}-\frac{\lambda}{2} r \quad \text { (Conservation of the absolute angular momentum) }
\end{aligned}
$$

where $\Omega$ is the absolute angular momentum.

Introducing the above value of $v_{r}$ into $(5 \cdot 2)$, we get $v_{\theta}^{\prime}$ by numerical calculation and hence introducing $v$. and $v_{\theta}^{\prime}$ into $(5 \cdot 1)$, we get the distribution of pressure gradient $\partial p^{\prime} / \partial r$ by numerical calculation. Putting $p_{0}{ }^{\prime}=p_{0}$, we have the new pressure distibution $p^{\prime}$ of
typhoons.

We will consider the motion of air particles for this pressure distribution. Introducing 
$p^{\prime}$ into (5.3), $V_{r}$ and $V_{\theta}$ are easily obtained from (5.3) and (5.4). On the other hand $v$, and $v_{\theta}{ }^{\prime}$ are the wind velocities when $k \neq 0$. Hence; comparing the two motions, the effect of friction is ensily estimaled. From the following figures the motions are approximately equal, hence the effect of friction is negligible at least when we deal the motion at the beginning.

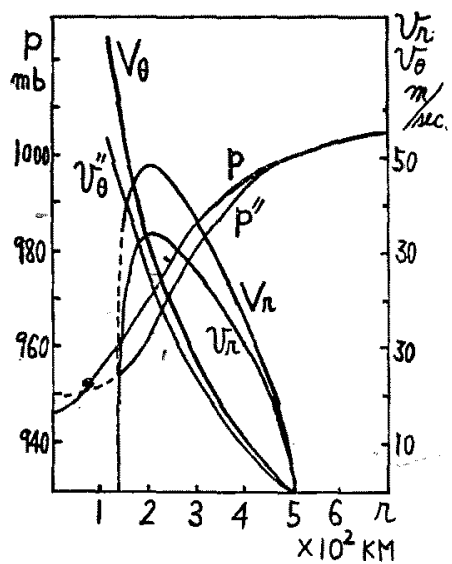

Fig. 5.1

The variation of tangential velocities $T_{\theta}, v_{\theta}{ }^{\prime \prime}$ and radial velocities $V_{n}$, $v_{j}$. of an air particle which converges from $r=500 \mathrm{~km}$, under the condition that an initial motion is zero.

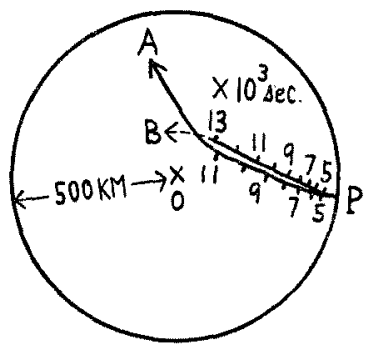

Fig. $5 \cdot 2$

Trajectory of an air particle which converges from point $P$ $(r=500 \mathrm{~km})$, under the condition that an initial motion is zero.

However, the above conclusion can not be applied to air particles in a well developed typhoon.

If the motion is stationary, from (5.1) and (5.2), we have

$$
\begin{aligned}
& v_{r} \frac{\partial v_{r}}{\partial r}-\frac{v_{\theta}{ }^{2}}{r}-\lambda v_{\theta}=-\frac{1}{\rho} \frac{\partial p}{\partial r}-k v_{r}, \\
& v_{r} \frac{\partial v_{\theta}}{\partial r}+\frac{v_{r} v_{\theta}}{r}+\lambda v_{r}=-k v_{\theta}
\end{aligned}
$$

or

$$
\begin{aligned}
-v_{\theta} Z & =-\frac{1}{\rho} \frac{\partial P}{\partial r}-k v_{r}, \\
v_{r} Z & =-k v_{\theta}
\end{aligned}
$$

where $Z$ is the absolute vorticity and $Z \equiv \frac{\partial v_{\theta}}{\partial r}+\frac{v_{\theta}}{r}+\lambda, P$ the total pressure and $P \equiv p+\frac{1}{2} \rho\left(v^{2}+v_{\theta}{ }^{2}\right)$. From $(5 \cdot 7)$ and $(5 \cdot 8)$, we have

$$
\begin{gathered}
v_{r}=-\frac{Z k}{Z^{2}+k^{2}} v_{\theta g} \\
-9-
\end{gathered}
$$




$$
v_{\theta}=\frac{Z^{2}}{Z^{2}+k^{2}} v_{\theta \sigma}
$$

where $v_{\theta g}$ is the gradient wind.

Accordingly, the convergence $\left(v_{2}<0\right)$ is considered to be caused by the effect of friction, because if $k=0, v$, becomes zero and converging currents vanish.

\section{\$ 6. Energy equation}

T. Ando investigated energy sources and their transformation.

By the equations of motion of the atmosphere

$$
\begin{aligned}
\frac{d u}{d t}+2 \omega \cos \theta \cdot w-2 \omega \sin \theta \cdot v & =-\frac{1}{\rho} \frac{\partial p}{\partial x} \\
\frac{d v}{d t}+2 \omega \sin \theta \cdot u & =-\frac{1}{\rho} \frac{\partial p}{\partial y} \\
\frac{d w}{d t}-2 \omega \cos \theta \cdot u & =-\frac{1}{\rho} \frac{\partial p}{\partial z}-g
\end{aligned}
$$

we have

$$
\begin{gathered}
\frac{d}{d t} \frac{\rho}{2}\left(u^{2}+v^{2}+w^{2}\right)-\frac{\left(u^{2}+v^{2}+w^{2}\right)}{2} \frac{d \rho}{d t}=-\left(\frac{\partial u p}{\partial x}+\frac{\partial v p}{\partial y}+\frac{\partial w p}{\partial z}\right) \\
+p\left(\frac{\partial u}{\partial x}+\frac{\partial v}{\partial y}+\frac{\partial w}{\partial z}\right)-\rho g w
\end{gathered}
$$

Introducing the equation of continuity, we have

$$
\begin{aligned}
\frac{d}{d t} & \frac{\rho}{2}\left(u^{2}+v^{2}+w^{2}\right)+\frac{\rho\left(u^{2}+v^{2}+w^{2}\right)}{2}\left(\frac{\partial u}{\partial x}+\frac{\partial v}{\partial y}+\frac{\partial w}{\partial z}\right) \\
& =-\left(\frac{\partial u p}{\partial x}+\frac{\partial v p}{\partial y}+\frac{\partial w p}{\partial z}\right)+p\left(\frac{\partial u}{\partial x}+\frac{\partial v}{\partial y}+\frac{\partial w}{\partial z}\right)-\rho g w
\end{aligned}
$$

Putting

$$
K_{E}=\frac{\rho}{2}\left(u^{2}+v^{2}+w^{2}\right), \quad \operatorname{div}_{3} V=\frac{\partial u}{\partial x}+\frac{\partial v}{\partial y}+\frac{\partial w}{\partial z} . \quad \operatorname{div}_{3} p V=\frac{\partial u p}{\partial x}+\frac{\partial v p}{\partial y}+\frac{\partial w p}{\partial z}
$$

we have

$$
\frac{d K_{E}}{d t}+K_{E} \operatorname{div}_{3} V=-\operatorname{div}_{3} p V+p \operatorname{div}_{3} V-\rho g w
$$

or

$$
\frac{\partial K_{E}}{\partial t}+\operatorname{div}_{3} K_{E} V=-\operatorname{div}_{3} p V+p \operatorname{div}_{3} V-\rho g w
$$

The left hand sides of $(6.5)$ and $(6 \cdot 6)$ are quite similar to the equation of continuity, therefore, the right hand sides may be considered to be kinetic energy source or kinetic energy production. Integrating the above formula for the total volume, we have

$$
\begin{aligned}
\iiint \frac{\partial K_{E}}{\partial t} d \mathrm{~V}= & -\iiint \operatorname{div}_{3} K_{\mathcal{E}} V d \mathrm{~V}-\iiint \operatorname{div}_{3} p V d \mathrm{~V} \\
& +\iiint p \operatorname{div}_{3} V d \mathrm{~V}-\iiint \rho g w d \mathrm{~V}
\end{aligned}
$$

By Gauss' thorem, 


$$
\iiint \frac{\partial K_{E}}{\partial t} d \mathrm{~V}=\iint\left(K_{E}+p\right) v_{n} d s+\iiint p \operatorname{div}_{3} V d \mathrm{~V}-\iiint \rho g w d \mathbf{V}
$$

This is the equation of energy for the whole system, such as a typhoon. Estimating the order of each term, we have, $p \operatorname{div}_{3} V=0(10), \rho g w=0(1), p v_{n}=0\left(10^{7}\right)$. Therefore, the first term of the right hand side of $(6.8)$, that is, the energy flow through the boundary, can not be reglected and the system can not be considered generally as closed. When we consider the general circulation, however, the surface integral vanishes, but $\iiint p \operatorname{div}_{3} V d V$ and $\iiint \rho g w d \mathrm{~V}$ do not. If the pressure in divergence zones is larger than the pressure in convergence zones, $\iiint p \operatorname{div}_{3} V d V$ is a source of kinetic energy. Accordingly, anticyclones are considered to be sources of kinetic energy and cyclones to be sinks. Combining $p \operatorname{div} V$ with the first law of thermodynamics, we have

$$
p \operatorname{div} V=\rho \frac{d Q}{d t}-J \rho c_{v} \frac{d I}{d t} .
$$

Accordingly, $d Q / d t$ is considered to be a source of kinetic energy.

Next, the potential energy $U$ per unit column is $\rho g z$. Hence

$$
\begin{gathered}
\frac{d U}{d t}=g z \frac{d \rho}{d t}+\rho g \frac{d z}{d t}=-U \operatorname{div}_{3} V+\rho g w \\
\frac{d U}{d t}+U \operatorname{div}_{3} V=\rho g w
\end{gathered}
$$

or

$$
\frac{\partial U}{\partial t}+\operatorname{div}_{3} U V=\rho g w
$$

Therefore, the energy source of potential energy is the upward motion against the gravity.

Integrating the equation with respect to volume, we have the potential energy of the whole system,

$$
\iiint \frac{\partial U}{\partial t} d V=\iint U V_{n} d s+g \iiint_{d} \rho_{w} d V
$$

From the first law of thermodynamics and putting $J c_{v} \rho T=I_{E}$, we get

$$
\frac{d I_{E}}{d t}+I_{E} \operatorname{div}_{3} V=\frac{p}{\rho} \frac{d \rho}{d t}+\rho \frac{d Q}{d t}
$$

or

$$
\frac{\partial I_{E}}{\partial t}+\operatorname{div}_{3} I_{E} V=\frac{p}{\rho} \frac{d \rho}{d t}+\rho \frac{d Q}{d t} .
$$

Integrating this equation, we have

$$
\iiint \frac{\partial I_{E}}{\partial t} d \mathrm{~V}=\iiint I_{E} v_{n} d s-\iiint p \operatorname{div}_{3} V d \mathrm{~V}+\iiint \rho \frac{d Q}{d t} d \mathrm{~V}
$$

From $(6 \cdot 6),(6.9)$ and $(6 \cdot 12)$, we have 


$$
\begin{aligned}
& \frac{\partial U^{*}}{\partial t}=\iint U V_{n} d s+\iiint \rho g w d \mathrm{~V} \\
& \frac{\partial K_{E^{*}}^{*}}{\partial t}=\iint K_{E} v_{n} d s+\iint p v_{n} d s+\iiint p \operatorname{div}_{3} V d \mathrm{~V}-\iint \rho g v d \mathrm{~V} \\
& \frac{\partial I_{E}^{*}}{\partial t}=\iint I_{E} V_{n} d s-\iiint p \operatorname{div}_{3} V d \mathrm{~V}+\iiint \rho \frac{d Q}{d t} d \mathrm{~V}
\end{aligned}
$$

where * means $\iiint \frac{\partial U}{\partial t} d V=\frac{\partial U^{*}}{\partial t}$, etc.

$\iiint \rho g u d V$ is contained in $(6 \cdot 6)$ and $(6 \cdot 9)$ but in opposite signs. This shows that the amount of decrease of potential energy caused by vertical motion is equal to that of increase of kinetic energy. $\iiint p \operatorname{div}_{3} V d V$ is contained in (6.6) and (6.12) but again in opposite signs. This also shows that the amount of decrease of kinetic energy is equal to the amount of increase of internal energy. In other words, this shows that a particle moved by pressure gradient gains kinetic cnergy and at the same time, a particle expands against pressure and its internal energy decreases. It is worthy of note that vertical motions are generally considered to accompany with divergence or convergence. Hence, if $\rho g w<0$, $p \operatorname{div}_{3} V=-R T \frac{d \rho}{d t}$ is generally negative. Accordingly, in order to estimate the net increase of kinetic energy by the decrease of potential energy caused by vertical motions, we must consider at the same time both $p \operatorname{div}_{3} V$ and $p V_{n}$. In a elosed system, difference between $p \operatorname{div}_{3} V$ and $\rho g w$ is the net increase of kinetic energy.

\section{$\$ 7$. Estimation of various energies of typhoons}

K. Takahashi derived semi-theoretical formulae which are used for estimating the various energies of typhoons. The following assumptions were made:

(1) The pressure distribution in typhoons is expressed by

$$
p=p_{0}-\frac{\Delta p_{0}}{1+\frac{r}{r_{0}}}
$$

where $p_{0}, \Delta p_{0}$ and $r_{0}$ are characteristic constants of typhoons,

(2) The height $H$ of a typhoon is about $10 \mathrm{~km}$, and $\Delta_{p_{0}}$ decreases linearly with elevation,

(3) The winds in typhoons are almost cyclostrophic,

(4) The radius $R$ of a typhoon is defined as the largest of the radii of almost circular isobars, and empirically, $R$ is proportional to the constant $r_{0}$,

(5) The eddy kinematic viscosity $\nu$ is proportional to the square of the wind speed,

(6) The energy loss due to friction is calculated by the theoretical results derived by Prof. S. Syono.

The results of the calculations are as follows: 
Pressure gradient

$$
G=\frac{\Delta p}{r_{0}\left(1+\frac{r}{r_{0}}\right)^{2}}
$$

Wind velocity

$$
v=\sqrt{\frac{\Delta p}{\rho} \frac{\sqrt{\frac{r}{r_{0}}}}{1+\frac{r}{r_{0}}}}
$$

Vorticity

Thickness of frietional layer

$$
\zeta=\frac{1}{2 r_{0}} \sqrt{\frac{\Delta}{\rho}} \frac{3+\frac{r}{r_{0}}}{\left(1+\frac{r}{r_{0}}\right)^{2} \sqrt{\frac{r}{r_{0}}}}
$$

$$
D=2 \pi \sqrt{K r_{0}}\left(\frac{\Delta p}{\rho}\right)^{\frac{1}{4}} \frac{\left(\frac{r}{r_{0}}\right)^{\frac{3}{4}}}{\sqrt{3+\frac{r}{r_{0}}}}
$$

Kinetic energy of wind

$$
K=\pi \Delta p_{0} H R^{2}\left\{\frac{\log (1+a)}{a^{2}}-\frac{1}{a(1+a)}\right\}
$$

Energy of pressure

$$
U=\pi \Delta p_{0} H R^{2}\left\{\frac{1}{a^{2}}-\frac{\log (1+a)}{a}\right\}
$$

Energy loss dne to surface friction per unit time

$$
W_{F}=2 \pi \beta^{3} \rho_{\kappa}\left(\frac{\Delta p}{\rho}\right)^{z}-\frac{R^{2}}{a^{2}} \int_{0}^{a} \frac{\xi^{2}}{(1+\xi)^{3}} d \xi
$$

Energy loss due to wind shear per unit time

$$
W_{a}=2 \pi \rho \sqrt{k} \sin ^{2} \alpha\left(\frac{\Delta p}{\rho}\right)^{1 \frac{3}{4}} \frac{R^{2}}{a^{3 / 2}} \int_{0}^{a} \xi^{9 / 4} \frac{\sqrt{3+\xi}}{(1+\xi)^{4}} d \xi
$$

Energy supply due to pressure gradient and the flow of kinetic energy

$$
W_{p}=\pi \rho \sqrt{k} \sin 2 \alpha R^{1 \frac{1}{2}}\left(\frac{\Delta p}{\rho}\right)^{1 \frac{3}{4}} \int_{0}^{a} \frac{\xi^{2}+\sqrt{3+\xi}}{a^{1 \frac{1}{2}}(1+\xi)^{\frac{1}{2}}} d \xi
$$

Mass of inflow per unit time from outside of typhoon assuming the winds as geostrophic

$$
m=\sqrt{2 h} \pi \rho \sin 2 \alpha\left(\frac{\Delta_{p}}{\rho}\right)^{2} \frac{a^{2}}{k \lambda^{5 / 2}(1+a)^{4}}
$$

Mass of convergence per unitio time

$$
Q=\frac{\sqrt{k}}{4 \sqrt{r_{0}}}\left(\frac{\Delta p}{\rho}\right)^{\frac{3}{4}} \sin 2 \alpha \frac{\left(\frac{r}{r_{0}}\right)^{\frac{1}{4}}\left(27+22 \frac{r}{r_{0}}+3\left(\frac{r}{r_{0}}\right)^{2}\right)}{\left(1+\frac{r}{r_{0}}\right)^{2}\left(3+\frac{r}{r_{0}}\right)^{\frac{3}{2}}}
$$

where $\kappa$ is the coefficient of surface friction, $\rho$ the density of air, $\alpha$ the angle between the deviation of surface winds and that of surface isobars, $k$ the proportional coefficient between. 
the kinematic eddy viscosity and the square of wind velocity, $a$ the proportional coefficient between $r_{0}$ and $R, \beta$ the proportional constant between surface wind and gradient wind.

The above equations are adjusted numerically so as to fit the typhoons by assuming that the winds in typhoons are approximately gradient winds.

$$
\text { Putting } \quad \begin{aligned}
\rho & =1.1 \times 10^{-3} \mathrm{gr} / \mathrm{cm}^{3}, \quad \underline{a}=5, \quad H=10 \mathrm{~km}, \quad \kappa=0.005 \text { C. G. S., } \\
\beta & =0.7, \quad \alpha=30^{\circ}, \quad K=0.5 \text { C.G.S. }
\end{aligned}
$$

we have the following results.

Kinetic energy of typhoons $\quad 0.36 \times 10^{22} \Delta p R^{2} \mathrm{erg}$.

Energy of the pressure of typhoons

$$
0.49 \times 10^{23} A p R^{2} \text { erg. }
$$

Loss of energy per unit time due to suriace slip

$$
1.9 \times 10^{16} \Delta_{p^{3 / 2}} R^{2} \mathrm{erg} / \mathrm{sec} .
$$

Loss of energy per unit time due to the winds shear in air

$$
\text { 2. } 0 \times 10^{16} \Delta p^{1 \frac{3}{4}} R^{3 / 2} \mathrm{erg} / \mathrm{sec} \text {. }
$$

Supply of energy due to pressure gradient and the flow of kinetic energy

$$
6.6 \times 10^{16} R^{1 \frac{1}{2}} \Delta p^{1 \frac{3}{4}} \text {. }
$$

Mass of inflow per unit time

$$
0.94 \times 10^{10} \frac{\Delta p^{2}}{R \sin ^{5 / 2} \phi} \text {. }
$$

Mass of convergence

$$
2.4 \frac{(\Delta p)^{4 / 3}}{\sqrt{R}} \frac{\xi^{1 / 4}\left(27+22 \xi+2 \xi^{2}\right)}{(1+\xi)^{2}(3+\xi)^{3 / 2}}
$$

\begin{tabular}{|c|c|c|c|c|c|c|}
\hline & Name & Date & $\Delta p$ & $R$ & Kinetic energy & Energy of pressure \\
\hline 1 & Muroto & 1934 Sep. 21 & $100 \mathrm{mb}$ & $7.6111 \mathrm{~km}$ & $2.1 \times 10^{25} \mathrm{erg}$ & $2.9 \times 10^{26} \mathrm{erg}$ \\
\hline 2 & Makurazaki & 1945 Sep. 17 & 95 & 7.0 & 1.7 & 2.3 \\
\hline 3 & Kitty & 1949 Aug. 31 & 54 & 4.7 & $4.2 \times 10^{24}$ & $5.8 \times 10^{25}$ \\
\hline 4 & Yasimamaru & 1933 Oct. 18 & 58 & 4.5 & 4.2 & 5.7 \\
\hline 5 & Jane & 1950 Sep. 3 & 58 & 3.5 & 2.5 & 3.5 \\
\hline 6 & Midget & 1939 Aug. 5 & 40 & 1.7 & $5.0 \times 10^{23}$ & $6.9 \times 10^{24}$ \\
\hline 7 & Hester & 1949 Jul. 29 & 14 & 1.5 & 1.1 & 1.5 \\
\hline
\end{tabular}

where unit of pressure is $\mathrm{mb}$, unit of the radius of typhoons is $111 \mathrm{~km}$. Thus the various energies in typhoons are estimated if only the radius and the deepness of pressure, or in other words, the central pressure are known'

In Table (7.1) some examples, calculated by these formulae, are shown. We see that the values agree with the numerically calculated values by Dr. Horiguti and T. Ando at

Table 7.1 Energies of typhoons. 


\begin{tabular}{|c|c|c|c|}
\hline & Energy loss surface friction & Wind shear & Mass of inflow \\
\hline 1 & $1.1 \times 10^{21} \mathrm{erg} / \mathrm{sec}$ & $1.3 \times 10^{21} \mathrm{erg} / \mathrm{sec}$ & $1.7 \times 10^{13} \mathrm{gr} / \mathrm{sec}$ \\
\hline 2 & 0.8 & 1.1 & 1.8 \\
\hline 3 & $1.7 \times 10^{20}$ & $2.2 \times 10^{20}$ & 0.8 \\
\hline 4 & 1.7 & 2.3 & 1.0 \\
\hline 5 & 1.0 & 1.6 & 1.3 \\
\hline 6 & $1.4 \times 10^{19}$ & $1.1 \times 10^{19}$ & 1.2 \\
\hline 7 & 0.2 & $0.4 \quad$ & 0.2 \\
\hline
\end{tabular}

least in their order of magnitude. And it is interesting to see that the amounts of the mass of inflow are almost equal for typhoons of different scales.

\section{\$ 8. Energies of the typhoons Kitty and Kezia}

T. Ando calculated numerically the various kinds of energy of the typhoons Kitty and Kezia by using the upper air observations as far as possible, and surface data observed on islands, such as Hachijojima and Yakushima to avoid the effect of topography. It was also assumed that the typhoons are almost stationary. Though it is difficult to define the boundary of typhoons, the area of typhoons may be determined as follows:

(1) The area within the largest and almost circular

Fig. 8.1 isobar.

(2) The area of the rainy region due to the direct effect of typhoon.

(3) From upper wind $(10,000 \mathrm{ft})$ distributions (an example is shown in Fig. 8.1) we can estimate the typhoon area.

(4) The positive vorticity area is estimated by the tangential velocity distribution as shown in Fig. 8.2.

These four areas, thus estimated, give almost the same values at least for Kitty and Kezia and the radii are found to be almost $600 \mathrm{~km}$. The heights of the typhoons Kitty and Kezia are assumed to be $12 \mathrm{~km}$. and $14 \mathrm{~km}$. respectively. Calculations were performed by the following formula for numerical integrations dividing the typhoon areas into rings of $100 \mathrm{~km}$. width and $1 \mathrm{~km}$. thickness.

Internal energy $I$ and potential energy $U$ are given by
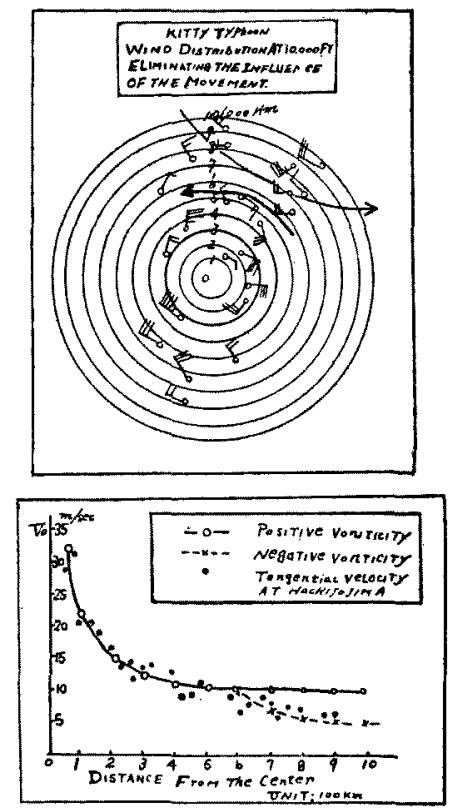

Eig. 8.2

$$
I=J c_{v} \int_{z_{3}}^{z_{2}} \rho T d z=\frac{J e_{v}}{R} \int_{\dot{z}_{1}}^{z_{2}} p d z=\frac{J c_{\mathcal{V}_{v}}}{R} \bar{p} \Delta z=2.5 \bar{p} \Delta z
$$

where 


$$
\begin{aligned}
& J=4.18 \times 10^{7} \mathrm{erg} / \mathrm{cal}, \quad R=2.87 \times 10^{6} \mathrm{erg} / \mathrm{gr} \mathrm{deg}, \quad c_{v}=0.1714 \mathrm{cal} / \mathrm{gr}, \\
& U=\int_{z_{1}}^{z_{2}} \rho g z d z=\int_{p_{z 2}}^{p_{z 1}} z d p=[p z]_{z 2}^{z_{1}}+\int_{z_{1}}^{z_{2}} p d z=\left(p_{z 1} z_{1}-p_{z z_{2}} z_{2}\right)+\bar{p} \Delta z . \\
& K=\int_{z_{1}}^{z_{2}} \frac{\rho\left(u^{2}+v^{2}\right)}{2} d z .
\end{aligned}
$$

and kinetic energy by

Dissipation energy due to friction by

$$
\int \rho K\left(u \frac{\partial u}{\partial z}+v \frac{\partial v}{\partial z}\right)_{z=0} \quad \text { where } \quad K=5 \times 10^{5} \text { C. G. S. }
$$

\begin{tabular}{|c|c|c|c|c|c|c|}
\hline $\begin{array}{c}\text { Distance from the } \\
\text { center }\end{array}$ & $600 \sim 500$ & $500 \sim 400$ & $400 \sim 300$ & $300 \sim 200$ & $200 \sim 100$ & $100 \sim 0 \mathrm{~km}$. \\
\hline Kinetic energy & 0.345 & 0.642 & 0.890 & 1.33 & 1.64 & $1.62 \times 10^{3} \mathrm{erg}$ \\
\hline Potential energy & 3.6 & 3.7 & 3.6 & 3.6 & 3.6 & $3.6 \times 10^{11} \mathrm{erg}$ \\
\hline Internal euergy & 1.52 & 1.54 & 1.54 & 1.53 & 1.52 & $1.52 \times 10^{12} \mathrm{erg}$ \\
\hline Latent heat energy & 10.9 & 13.5 & 14.3 & 15.6 & 15.1 & $15.6 \times 10^{10} \mathrm{erg}$ \\
\hline $\begin{array}{l}\text { Energy released by } \\
\text { condesation }\end{array}$ & 0 & 0 & 0.45 & 3.26 & 6.90 & $10.9 \times 10^{6} \mathrm{erg} / \mathrm{sec}$ \\
\hline $\begin{array}{l}\text { Dissipated energy } \\
\text { due to surface slip }\end{array}$ & 0.6 & 0.7 & 1.04 & 1.14 & 2.14 & $1.20 \times 10^{4} \mathrm{erg} / \mathrm{sec}$ \\
\hline \multicolumn{7}{|c|}{ Kezia } \\
\hline $\begin{array}{l}\text { Distance from the } \\
\text { center }\end{array}$ & $600 \sim 500$ & $500 \sim 400$ & $400 \sim 300$ & $300 \sim 200$ & $200 \sim 100$ & $100 \sim 0 \mathrm{~km}$ \\
\hline Kinetic energy & 1.42 & 2.06 & 3.42 & 4.26 & 4.73 & $2.03 \times 10^{9} \mathrm{erg}$ \\
\hline Potential energy & 4.4 & 4.4 & 4.4 & 4.4 & 4.3 & $4.3 \times 10^{11} \mathrm{erg}$ \\
\hline Internal energy & 1.66 & 1.66 & 1.66 & 1.65 & 1.65 & $1.64 \times 10^{12} \mathrm{erg}$ \\
\hline Latent heat energy & 14.5 & 16.9 & 16.6 & 15.9 & 16.1 & $16.5 \times 10^{10} \mathrm{erg}$ \\
\hline $\begin{array}{l}\text { Energy released by } \\
\text { condensation }\end{array}$ & 0 & 0.39 & 0.70 & 1.92 & 2.66 & $8.60 \times 10^{6} \mathrm{erg} / \mathrm{sec}$ \\
\hline $\begin{array}{l}\text { Dissipated energy } \\
\text { due to suriace slip }\end{array}$ & 0.5 & 1.95 & 1.75 & 1.74 & 3.42 & $3.12 \times 10^{4} \mathrm{erg} / \mathrm{sec}$ \\
\hline
\end{tabular}

Energy released by condensation is also calculated from the amount of rain. Calculated values of various energies are as follows:

Table 8.1 Energies in each ring in the typhoons Kitty and Kezia.

Table 8.2 Energies of the typhoons Kitty and Kezia.

\begin{tabular}{l|c|c}
\hline \multicolumn{1}{c|}{ Typhoons } & Kitly (1949 Aug. 31 st) & Kezia (1950 Sep. 11 th) \\
\hline Kinetic energy & $8.71 \times 10^{24} \mathrm{erg}$ & $1.5 \times 10^{25} \mathrm{erg}$ \\
Internal energy & $1.73 \times 10^{26} \mathrm{erg}$ & $1.87 \times 10^{26} \mathrm{erg}$ \\
Potential energy & $0.41 \times 10^{26} \mathrm{erg}$ & $0.50 \times 10^{26} \mathrm{erg}$ \\
Latent heat energy & $1.51 \times 10^{27} \mathrm{erg}$ & $1.79 \times 10^{27} \mathrm{erg}$ \\
Energy released by condensation & $0.80 \times 10^{22} \mathrm{erg} / \mathrm{sec}$ & $0.54 \times 10^{22} \mathrm{erg} / \mathrm{sec}$ \\
Dissipated energy due to surface slip & $1.07 \times 10^{20} \mathrm{erg} / \mathrm{sec}^{*}$ & $1.80 \times 10^{26} \mathrm{erg} / \mathrm{sec}$ \\
\hline
\end{tabular}




\section{\$ 9. Damages caused by the typhoons and their magnitude}

Japan suffers from great damages by typhoons. The amount of damages generally depends on the radius and the central pressure of typhoon and K. Takahashi derived the empirical formulae:

$$
\begin{aligned}
& N=f \Delta p R^{2} t \\
& n=g \Delta p R^{2} t
\end{aligned}
$$

where $N$ is the number of utterly destroyed houses, $n$ the number of dead persons by typhoons, $f$ and $g$ are certain constants $t$ the time duration during which the internal area of typhoons considered is affected by the area. The values of $f$ and $g$ are about $1 / 10$ and $1 / 80$ respectively. The above equations express that the damage by typhoons is proportional to the kinetic energy of typhoon and the time duration. Accordingly, it may be natural to define that the magnitude of a typhoon is proportional to its kinetic energy like the magnitude of an earthquake.

In Fig. 9.1, the ordinate shows the amount of damage and the abscissa $\Delta p \cdot R^{2} \cdot t$. Though the points are scattered, we see that the above formulae hold roughly.

Discrepancy of the empirical formulae may be explained by various reasons, such as, the difficulties of estimation of the strength of construction, of the density of population, of topography, and so on. The study of these reason is left for the future.

Lastly, we wish to express our sincere thanks to

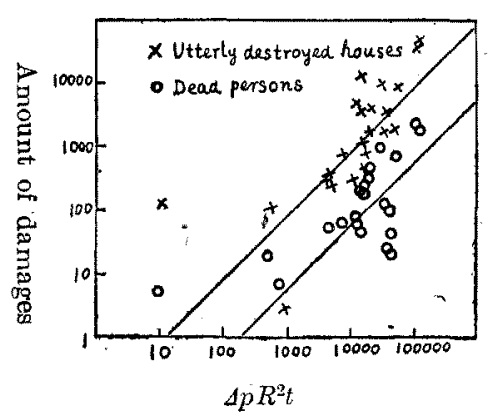

Fig. 9.1

Director H. Hatakeyama and Prof. S. Syono for their kind support of our studies.

At the Forecasting Laboratory of the Meteorological Research Institute attached to the Central Meteorological Observatory. 


\title{
台風の構造とエネルギー 高橋浩一郎* 渡边次雄* 售田正八* 安藤 正 $^{*}$ 中村則行 ${ }^{*}$
}

1950 年の夏にはしばしば豆台風が発生し，9月にはシュン一台風が近畿に上陸した。本論交は

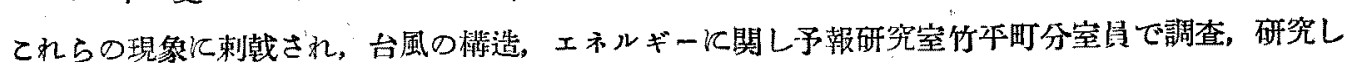
そ結果の概要であり，詳細は中英気象台基報にのる予定である。

为 1 篩で红等田が 1950 年夏, 本邦南方の熱帶低圧部を調査し, 矛 2 節は渡辺が台風眼の力学に

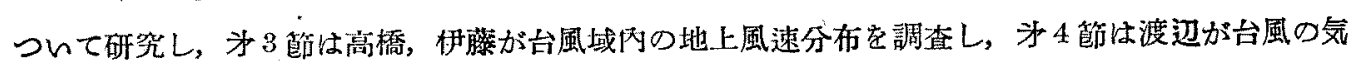

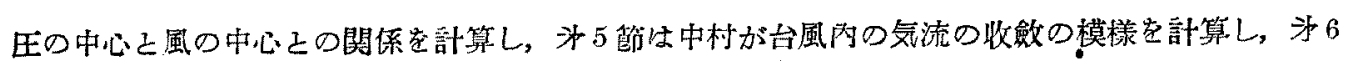

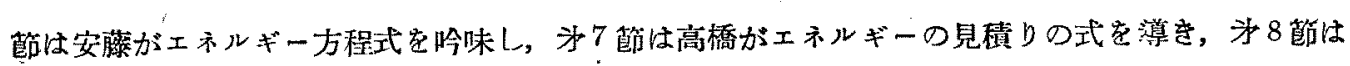
安藤がキティおよびキジ台風のエネルギーを見精り，矛 9 節は高橋が台風の規模之被害の程度之 の関係を調べを結果である。

\section{Tropopause in a Steady Zonal Wind Field}

\section{By H. Arakawa}

(Meteorological Research Institute)

\begin{abstract}
Summary
The relation of temperature and velocity to the slope of the tropopause in a steady zonal wind field is derived in spherical polar coordinates. Then, the tropopause "dip" just north of the jet streams in the westerlies is disctussed.

The relation of temperature and velocity to the slope of the tropopause in a geostrophic wind field was first derived by V. Bjerknes. (1) Further the relation of temperature and velocity to the slope of the tropopause in a gradient wind field was given by H. Ertel. ${ }^{(2)}$ The case treatd by $\mathrm{H}$. Ertel is admittedly a simple one, so it may not be adequate for the problem of the tropopause funnel. However, such a consideration will be of value as a preliminary to the discussion of a steady zonal wind field, though it must be admitted that the analysis will not be essentially new from that given by V. Bjerknes.
\end{abstract}

\footnotetext{
* 気解研究所.
} 